\title{
Picasso: esculturas en papel para un nuevo pensamiento estético
}

\author{
Ramón López de Benito \\ Universidad Complutense de Madrid \\ rlopezbe@ucm.es
}

RESUMEN: Aunque desde sus orígenes el papel estuvo ligado fundamentalmente a su finalidad como soporte para la escritura, pronto encontrará en el arte un medio en el que desplegar sus más audaces posibilidades creativas. Así los artistas lo han empleado como soporte en diferentes procedimientos artísticos como el dibujo, el grabado, la acuarela, etc. Técnicas que desde la bidimensionalidad del papel han contribuido a ensanchar los horizontes expresivos del arte. Sin embargo, resulta menos conocida la importancia que adquiere en el arte desde su conformación tridimensional. La irrupción del papel como material escultórico en el arte se produce a principios del siglo XX, en los inicios de la modernidad, teniendo a Picasso como principal referente. La proyección de sus trabajos realizados en papel, resultará determinante para entender buena parte de los postulados escultóricos de los primeros movimientos de vanguardia, influyendo de manera decisiva en el posterior desarrollo de la modernidad.

PALABRAS CLAVE: Picasso, Escultura, Modernidad, Construcción, Papiers Collés, Collage.

\section{Picasso: Paper Sculptures for a New Aesthetic Thought}

ABSTRACT: Although since its inception paper was mainly linked to its purpose as a support for writing, soon it found in art a medium in which to deploy its boldest creative possibilities. So artists have used it as support in different artistic techniques or procedures such as drawing, printmaking, watercolor, etc. Techniques from the two-dimensionality of paper have helped to broaden the expressive horizons of art. However, the importance acquired by its three dimensional conformation in art is less well known. The emergence of paper as sculptural material in art occurs in the early twentieth century, at the beginning of Modernism in art, with Picasso as the main point of reference. The projection of his works done in paper, will be crucial to understanding many of the sculptural postulates of the early avant-garde movements, and influence decisively in the later development of modern art.

KEYWORDS: Picasso, Sculpture, Modern Art, Construction, Papiers Collés, Collage.

Recibido: 13 de abril de 2016 / Aceptado: 9 de julio de 2016.

A finales del siglo XIX y principios del XX, la historia del arte experimenta la que puede considerarse sin duda la revolución artística más importante de todos los tiempos. El paso de la tradición a la modernidad supone la culminación de un proceso y el inicio de un horizonte nuevo, en el que la libertad creativa se había convertido en el anhelo y objetivo de los artistas más innovadores y comprometidos con la revitalización del panorama artístico.

Artistas como Pablo Picasso y Georges Braque, compañeros de investigación en la búsqueda de nuevas fórmulas para el arte, habían trabajado en estrecha colaboración sus respectivos proyectos pictóricos dando lugar a uno de los movimientos artísticos más importantes y apasionantes del siglo XX, el cubismo. Como primer movimiento de vanguardia, el cubismo rompe con algunos de los más consolidados presupuestos plásticos del pasado, otorgando una especial importancia a la reinterpretación del espacio como elemento vertebrador de la narración. La nueva configuración del espacio cubista hizo que

LÓPEZ DE BENITO, Ramón: «Picasso: esculturas en papel para un nuevo pensamiento estético», Boletín de Arte, n. ${ }^{\circ}$ 37, Departamento de Historia del Arte, Universidad de Málaga, 2016, pp. 129-138, ISSN: 0211-8483. 


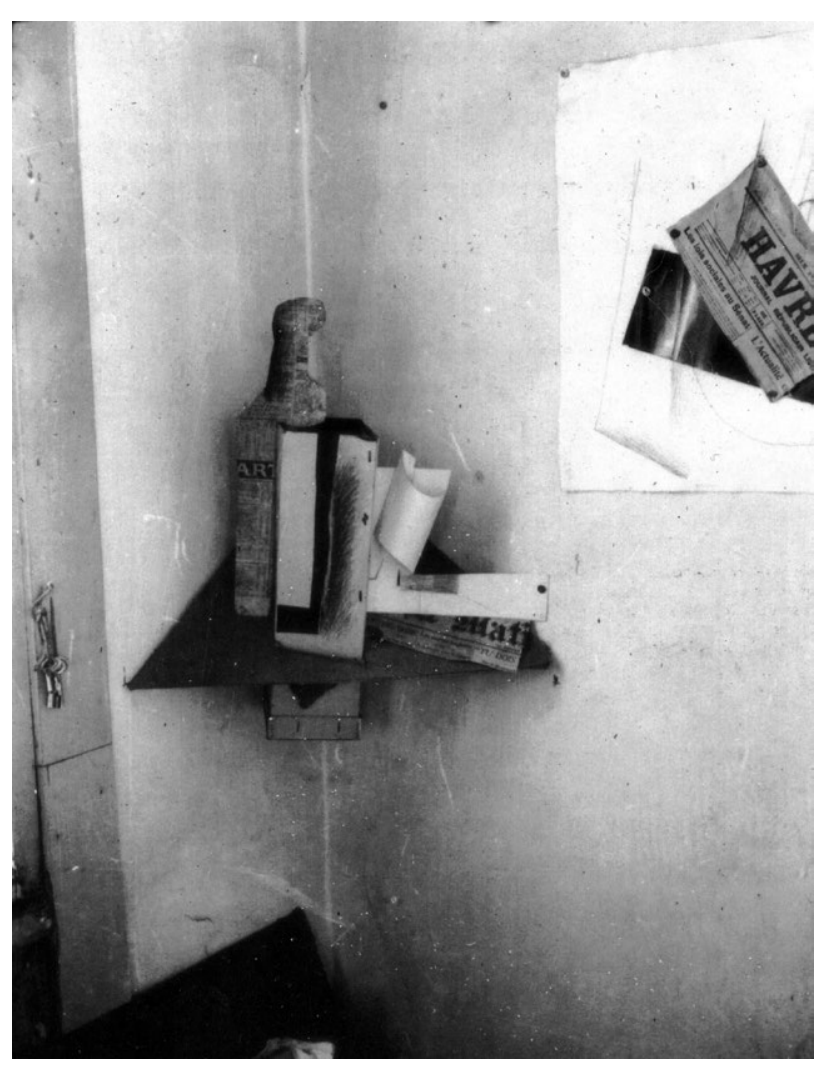

1. Construcción de Braque realizada en el Hotel Roma, primavera de 1914. Actualmente desaparecida

algunos aspectos vinculados al mismo como la perspectiva, el punto de vista único e incluso la forma, cobraran un nuevo sentido. Su interés por encontrar narraciones alternativas bajo esta nueva interpretación del espacio, les llevó a trascender la bidimensionalidad de la pintura para experimentar con la tridimensionalidad de la escultura.

Será precisamente en 1911, en los últimos tiempos del Cubismo Analítico, cuando Braque, en su búsqueda por aportar nuevas expresividades plásticas a la pintura, y tal vez consciente de que la verdadera revolución cubista dependía de una nueva configuración del espacio, realiza una serie de esculturas, pequeñas construcciones en papel de carácter tridimensional, donde todas sus reflexiones acerca del espacio y su manera de expresarlo, entran en una nueva fase. Actualmente se sabe poco sobre el aspecto que estas pequeñas esculturas pudieron tener, pues desgraciadamente no se conserva ninguna de ellas. Según explica William
Rubin: «Recorta el papel y el cartón con unas tijeras o una navaja de afeitar, lo arruga y lo dobla, tal vez lo coloca sobre un fondo y probablemente le aplica pintura o le añade dibujos» (Rubin, 1991: 33).

Sabemos que el interés de Braque por este tipo de construcciones continuó durante 1912, con la realización de una nueva serie de esculturas o construcciones en papel de las que también desconocemos su aspecto. Parece ser, según declaró el propio Braque a John Richardson cuando le preguntó al respecto: «Estaban hechas con recortes y trozos doblados de papel y cartón: algunas estaban coloreadas» (Richardson, 1997: 254).

Sea como fuere, Braque no pareció darles mucha importancia y finalmente terminaron por desaparecer, sin dejar testimonio de las mismas. Tan solo se conserva como referencia la fotografía [1] de una construcción tomada en el estudio del Hotel Roma en 1914, correspondiente a una pieza dispuesta en una esquina de la pared, realizada en papel y cartón. En ella aprovecha los planos de la pared y el espacio que se genera entre ellas para integrarlo de manera realmente interesante en la composición. Pero como he puntualizado, solo debe servirnos de referencia puesto que hay dos años de diferencia entre la realización de las primeras construcciones y la fotografiada en el Hotel Roma. En cualquier caso, de lo que no cabe duda es de que las primeras esculturas realizadas en papel por Braque aportarán un concepto novedoso a la escultura, el concepto de «construcción», la «escultura construida» o «ensamblaje». Un recurso que se conformará como alternativa a las tradicionales técnicas aditivas (modelado, vinculado al bronce como material) o sustractivas (vinculadas a las técnicas de la talla en madera o en piedra). El concepto de construcción será, por tanto, el vehículo que proporcione a partir de sus primeros ejemplos elaborados en papel, la posibilidad de incorporar nuevos materiales, técnicas y procedimientos al terreno de la escultura.

Sin duda las primeras esculturas realizadas en papel por Braque estimularon a Picasso a trabajar en la misma dirección que su compañero. Picasso llevaba tiempo buscando la manera de difuminar las diferencias entre pintura y escultura, intentando que el mensaje de su trabajo transcendiera la dimensionalidad de la obra, y en este sentido la construcción como técnica, fue el instrumento que mejor contribuyó a reforzar, o profundizar en esta idea. No es de extrañar, por tanto, que algunos de estos trabajos sirvieran 
de inspiración, e incluso de modelo para muchos de sus cuadros en los que se refleja el resultado de este análisis.

John Golding (destacado analista del cubismo) comenta en una sagaz, inteligente y en ocasiones discutible visión del movimiento cubista, que lo que condujo a Picasso hacia el cubismo fue su interés por analizar e investigar la naturaleza de las formas tridimensionales (1993: 66). Afirmación con la que estoy de acuerdo, aunque las palabras de Golding se refieran al plano pictórico, creo que es perfectamente extrapolable al conjunto de su obra. Podríamos incluso apreciar, más que un interés, la actitud con la que afronta el hecho artístico en sí. De este modo la articulación del espacio tridimensional, feudo tradicionalmente escultórico, se convierte en una de sus principales preocupaciones desde el principio del cubismo. Es lógico pensar, por tanto, que en algún momento de ese análisis, tuviera que enfrentarse con el espacio real como ente ineludible para completar la evolución lógica del cubismo con una mayor severidad. Sin duda esta actitud, acompañada de la idea de buscar nuevos recursos, o lenguajes alternativos con los que explicarlo de una manera coherente y comprometida con sus propuestas artísticas, fue lo que dio lugar a sus primeras esculturas en papel y por extensión a la idea de construcción.

Estos primeros ejemplos de construcción por ensamblaje realizados por Picasso, así como sus primeros papiers collés, se llevaron a cabo en el periodo de tiempo comprendido entre el otoño y el invierno de 1912 a 1913, y fueron realizados todos ellos en papel y cartón. Tres fotografías tomadas precisamente en su estudio del boulevard Raspail [2], fechadas a finales de noviembre-principios de diciembre de 1912 (4 de diciembre, 1912, Musée National Picasso, París), muestran, colgada en la pared de su estudio, la primera de sus construcciones, Guitarra (versión en cartón predecesora de la realizada posteriormente en metal). En una de las fotografías (arriba) podemos ver además (en la parte inferior derecha), otras dos pequeñas construcciones de menor tamaño (unos $30 \mathrm{~cm}$, aproximadamente), dos guitarras catalogadas como Spies 29 y 30 (Spies, 1971), que corresponden a la misma época, realizadas también en papel y cartón [3] y [4]. Las fotografías revelan tres momentos o versiones de la misma idea. En todas aparece la guitarra de cartón colgada en la pared, rodeada de dibujos y papiers collés en diferentes fases de realización, por lo que en cualquier caso, tanto las construcciones como los papiers collés que aparecen en dichas

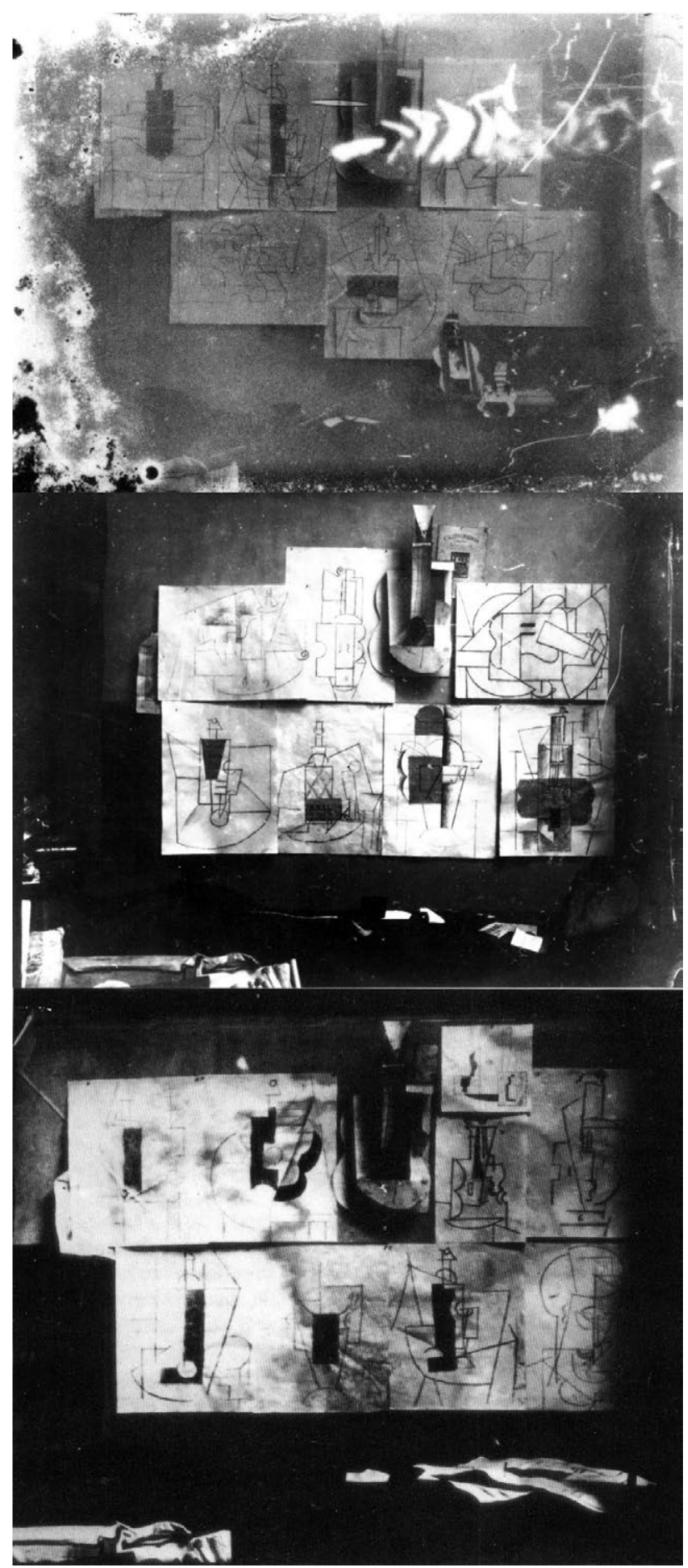

2. Guitarra, rodeada por seis dibujos y papiers collés; Guitarra rodeada por siete dibujos y papiers collés; Guitarra rodeada por nueve dibujos y papiers collés. Fotografías tomadas por Picasso de sus trabajos realizados en papel, en su estudio del Boulevard Raspail, finales de 1912. Archives Picasso, Musée National Picasso, París 


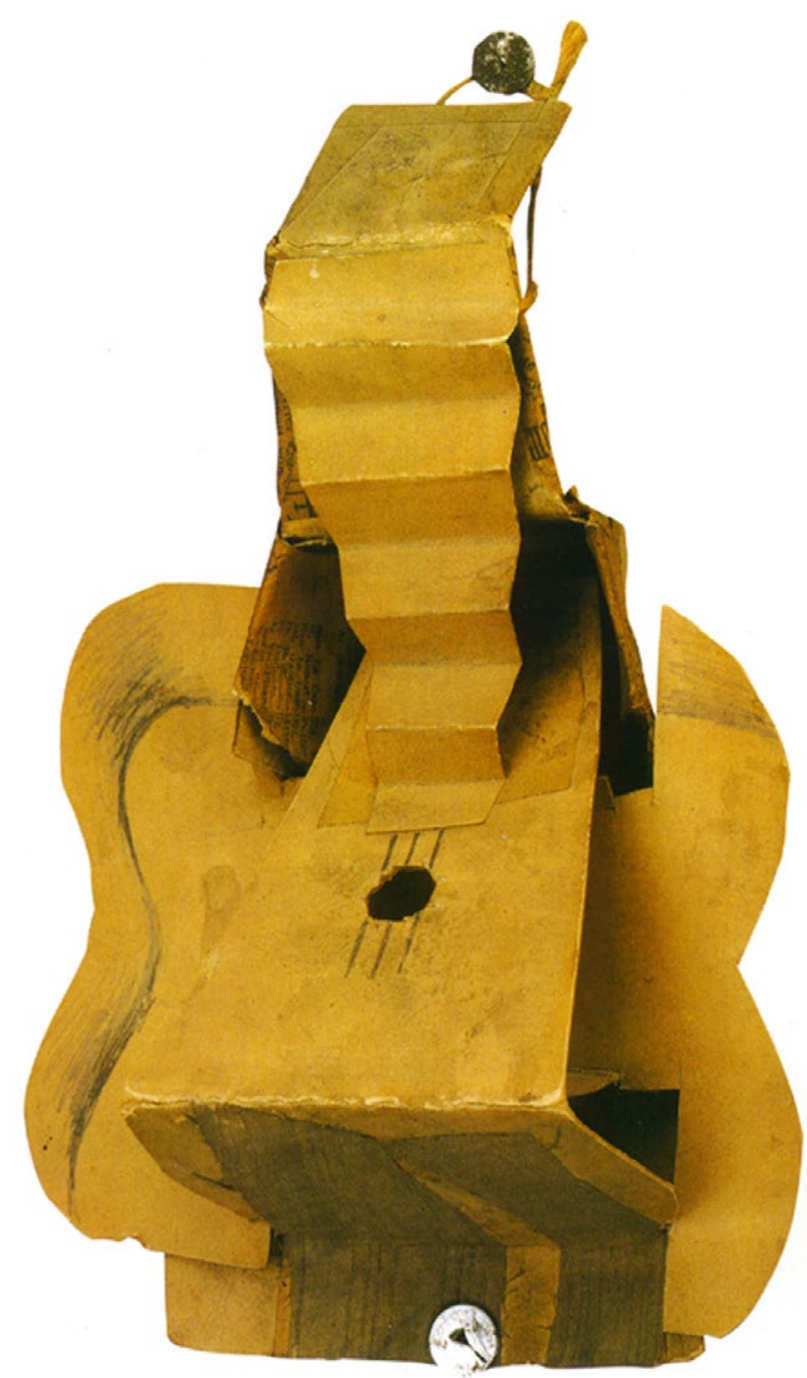

3. Guitarra. Picasso, 1912 (posterior a 3 de diciembre). Cartón recortado, papel, lienzo, bramante, óleo y lápiz. 33×18×9,5 cm (Spies 30). Musée Picasso, París

fotografías, debieron ser realizados a finales de 1912. Más difícil resulta determinar cuál de los dos conceptos o medios de expresión, la construcción o el papier collé, apareció antes en su obra, aspecto de indudable interés para entender el proceso evolutivo de estos trabajos, tanto en la obra de Picasso en particular, como en el desarrollo del cubismo en general.

Es muy posible que sus primeras construcciones también se desarrollaran con anterioridad, o al menos paralelamente, a sus primeros papiers collés, al contrario de la idea generalizada que los considera como una evolución lógica, o interpretación tridimensional de los mismos. Picasso siempre mantuvo que la Guitarra fue realizada antes de empezar sus primeros papiers collés. Así se lo dijo a William Rubin cuando ofreció la versión en metal de su guitarra al Museo de Arte Moderno de Nueva York (Rubin, 1991: 26) y es muy posible que así fuera. William Rubin, basándose en la fecha del recorte de periódico, sitúa la realización del primer papier collé de Picasso, Guitarra, partitura y vaso sobre una mesa "La Bataille s'est engagé[e]" (la batalla ha comenzado), en torno el 18 de noviembre (de 1912), de dar por buena la catalogación, deberíamos considerar sus primeras construcciones anteriores a los papiers collés. En cualquier caso también deberíamos tener en cuenta el collage, proceso plástico de enorme interés que podría relacionar los dos anteriormente mencionados, y que basa la conformación de la obra en la composición de elementos de diferente procedencia (no necesariamente papel o cartón como en el caso de los papiers collés). Precisamente el primer collage del que tenemos constancia, Naturaleza muerta con trenzado de siIla, fue realizado por Picasso en mayo de 1912, unos meses antes de realizar sus primeras construcciones tridimensionales y sus primeros papiers collés. Para su realización Picasso utilizó un trozo de hule estampado que imita una maya trenzada de las empleadas para sillas, y una soga real que rodea el cuadro a modo de marco. De este modo podemos entender el collage como antecedente en la idea de disolver las diferencias entre las dos y las tres dimensiones, introduciendo además un aspecto de gran interés para el arte, como la fluctuación entre la realidad y la representación que, de algún modo, también se palpa en los trabajos realizados en papel, y que en el futuro será audazmente aprovechado por artistas como Marcel Duchamp en sus ready mades.

Volviendo a las construcciones realizadas en papel objeto de estudio en este artículo, resulta interesante destacar que en sus primeras esculturas construidas en papel, el principal elemento narrativo (en todas ellas la guitarra), se presenta como objeto único e independiente de posibles vaIoraciones compositivas o contextuales, a diferencia de sus cuadros, e incluso de los papiers collés de la misma época. El objeto único adquiere, por tanto, todo el protagonismo y se convierte en un vehículo comunicador autónomo, lo que da lugar a un tipo de construcción que denominamos «construcción objeto». Este giro, o cambio en la estructura 
compositiva, nos hace pensar, que ante el reto que suponía lanzarse a una nueva interpretación del espacio cubista, Picasso decidiese aislar o reducir la complejidad del problema a las interacciones que dicho espacio suscita sobre un único objeto. Una vez resuelto el reto, y como veremos en sus próximos ensayos, aplicará las soluciones conseguidas a composiciones más amplias y complejas.

La guitarra, en su nueva identidad de construcción objeto, se convertirá por tanto en el principal valedor de sus primeras esculturas construidas. En ellas Picasso estudia la relación entre el objeto y el espacio, el material y la forma, la escultura y la pintura, a través de un sistema de representación, distinto y alternativo a los métodos convencionales, con el que cuestionará muchas de las premisas y compromisos plásticos imperantes hasta el momento. Picasso se percató inmediatamente de las enormes posibilidades que aquellas pequeñas construcciones de papel encerraban. Uno de los primeros resultados obtenidos, fruto de este análisis, es la reinterpretación del espacio como elemento escultórico. Con los nuevos procedimientos utilizados, Picasso consigue incorporar el espacio a la composición permitiendo que éste tome parte en la obra como un elemento compositivo más, y ofreciendo una nueva manera no ilusionista de entender la representación del mismo. De este modo reivindica el hueco o el volumen virtual como una de las aportaciones fundamentales en la escultura del siglo XX.

Los logros alcanzados en el tratamiento del espacio se deben en gran parte a la complicidad de los materiales empleados. Los primeros trabajos correspondientes a este periodo están realizados fundamentalmente con papel y cartón, donde el material se presenta como un elemento volumétricamente plano, en contraposición a los materiales tradicionales, como la piedra, la madera o el barro, que disponen por sí mismos de cualidades volumétricas. Tal vez en esa diferencia radique el éxito de sus construcciones. El uso de materiales volumétricamente planos, se convertirá por tanto en una de sus grandes aportaciones en la búsqueda de una nueva significación o extensión tridimensional del espacio, aspecto de enorme trascendencia en el futuro por las posibilidades que esto encierra, pues le permitirán ocupar y a la vez absorber el espacio tridimensional, dejando que éste fluya a través de la forma tomando parte en ella. De este modo, el espacio, tradicionalmente considerado negación o contraposición de la forma, se incorpora a ella, de una

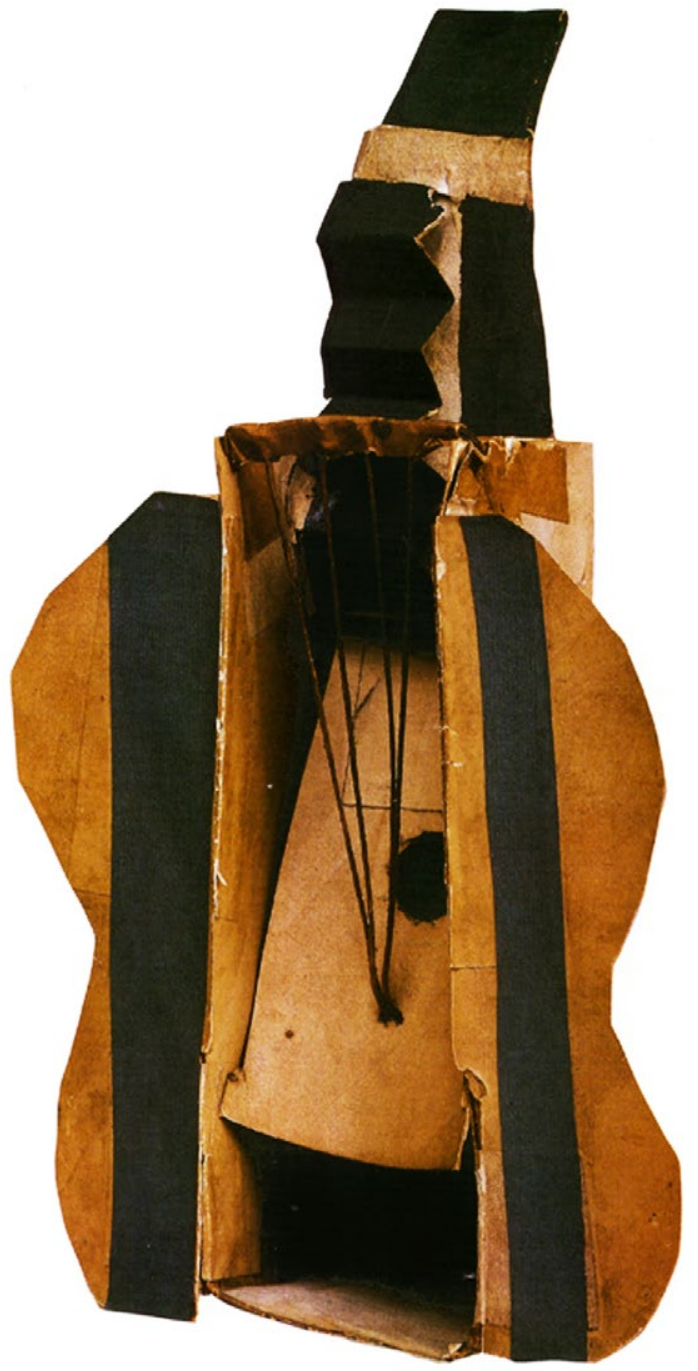

4. Guitarra. Picasso, 1912 (posterior a 3 de diciembre). Cartón recortado, papel, lienzo, bramante y lápiz. 22,8x14,5x7 cm (Spies 29). Musée Picasso, París

manera física, convirtiéndose, más que en un adversario, en cómplice de la misma. Si en las técnicas escultóricas tradicionales la forma había condicionado el material, ahora es el material el que contribuye a condicionar la forma, presentándose sin pudor como elemento comunicador no subyugado necesariamente a forzosos presupuestos formales. Este aspecto resulta particularmente interesante, pues de este modo la escultura se abre a la posibilidad de incluir nuevas oportunidades plásticas, y por consiguiente nuevos materia- 


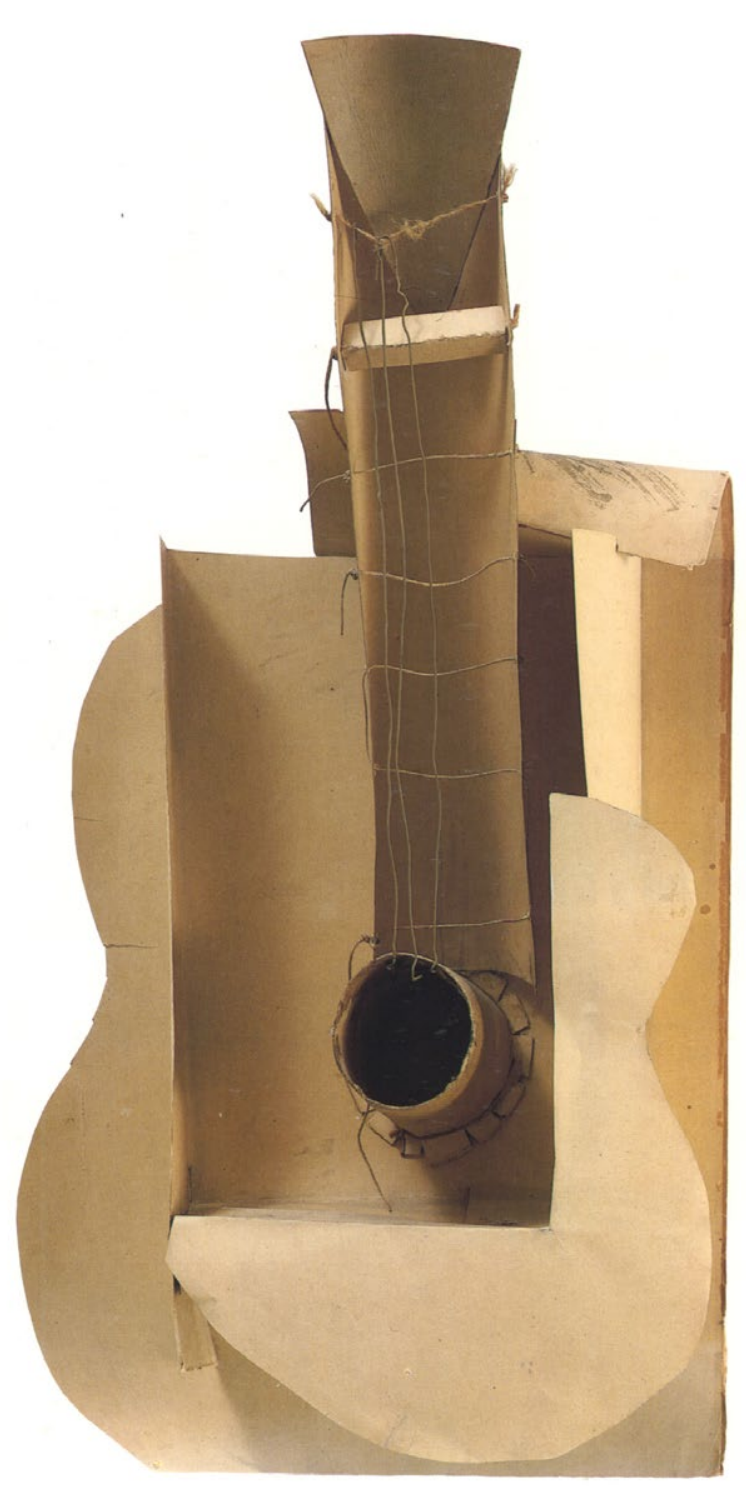

5. Guitarra. Picasso, otoño de 1912. Cartón y bramante. $65,1 \times 33 \times 19 \mathrm{~cm}$. The Museum of Modern Art, NuevaYork

les, al constreñido repertorio de procedimientos escultóricos vigente hasta el momento.

La incorporación del espacio a la escultura, traerá consigo la solución a algunas de las cuestiones planteadas desde hacía tiempo en su pintura, como la simultaneidad perceptiva, o coexistencia simultánea de diferentes aspectos de un modelo en la misma obra. Lo cual queda resuelto audazmente gracias a la «transparencia» que proporciona el hueco o volumen virtual, y que nos permite ver diversos puntos de vista de un objeto al mismo tiempo, sin duda una de las particularidades más llamativas de este primer grupo de construcciones. Así en el caso de la Guitarra [5], podemos ver simultáneamente, tanto el interior como el exterior, la parte delantera como la trasera, etc.

Lógicamente la idea de trabajar con materiales planos, demandaba nuevos mecanismos o procedimientos estilísticos que Picasso supo ver inmediatamente, asentando ya con sus primeros trabajos, las bases y fundamentos básicos de la escultura construida. La intuición que desprenden estos trabajos desvela una valiente armonización en el tratamiento del plano, la arista, o el hueco, con los que consigue nuevas apreciaciones, o valoraciones plásticas tanto en la forma, como en el claro-oscuro o la composición. El aprovechamiento del material en beneficio de la obra se convertirá por tanto en una de las cualidades más apreciables de su trabajo.

Los resultados conseguidos con sus primeras construcciones realizadas en cartón, realmente alentadores, le llevan a experimentar con un nuevo material, el hierro, con el que construye una guitarra, casi idéntica a la que había realizado anteriormente (en cartón). Esta nueva versión de Guitarra, supone la primera ocasión en la historia de la escultura en que el hierro es utilizado como único material para la elaboración de una obra plenamente comprometida con la realidad artística de su momento, mas allá del ornamento, la artesanía o la mera funcionalidad. Por lo que podemos considerarla precursora en la incorporación de nuevos materiales a la escultura de la modernidad, convirtiéndose así en trasmisora de innovadores planteamientos y valores para el arte.

Picasso recurrió a las formas de las plantillas de Guitarra (realizada en cartón), utilizándolas como elemento compositivo en varios de sus primeros papiers collés correspondientes a la misma época (concretamente en los que no intervienen otros elementos como el dibujo o la pintura), mostrando el parentesco y relación existente entre sus primeras construcciones y los papiers collés. Así pues, el papier collé es entendido como una manera de construir o estructurar el dibujo eliminando las diferencias entre la bidimensionalidad y la tridimensionalidad. La idea del objeto como escultura y a la vez como plano o plantilla con la que poder generar nuevas obras es tremendamente interesante, y responde a su idea de un arte popular, próximo a la gente. Picasso llegó a sugerir la posibilidad de que cualquiera pudiera realizar sus 
propias copias, utilizando las plantillas. Según comentó a A. Salmon en cierta ocasión (a propósito de su primera construcción en chapa, Guitarra de 1912): «Vas a ver, guardo el guitarrón, pero venderé el plano, todo el mundo podrá hacer lo mismo» (Salmon, 1956, referido en Rubin, 1991: 14, nota 26). Intención que no llegaría a materializarse. Las plantillas permanecieron en su estudio hasta su donación al Museo de Arte Moderno de Nueva York.

En el otoño de 1913, Picasso retoma sus trabajos volumétricos realizados en papel con una nueva composición catalogada como Guitarra y Botella [6]. En ella, la Guitarra, la primera de sus construcciones realizada en papel, aparece como personaje central de una construcción mural que Picasso ensambló igualmente sobre la pared de su nuevo estudio en la calle Schoelcher, como había hecho anteriormente con alguno de sus ensayos anteriores en el boulevard Raspail. La composición sitúa a la guitarra como parte de una escena, para evaluar de una manera más amplia la intervención del espacio en la propia obra, trascendiendo de este modo su carácter de construcción objeto.

El resultado final la convierte en una naturaleza muerta muy próxima a sus trabajos pictóricos, pudiendo haber servido de modelo para varios de sus lienzos y aportando un alcance compositivo más coherente que el obtenido con su anterior intervención realizada en el estudio del boulevard Raspail. Finalmente Picasso desmontó el ensamblaje, quedándose únicamente con la guitarra, con lo que esta recuperó su identidad original tal y como se conserva hoy en día.

Esta misma línea de investigación tendrá su continuidad en Violín [7], de 1913. Realizada con recortes de papel o cartón, guarda muchas similitudes con la anterior. En ella, el instrumento musical (en este caso un violín), aparece igualmente integrado en una composición más amplia. Un fondo de papel estampado (similar al utilizado por Picasso en sus papiers collés), viene a representar a modo de escenografía, la pared de la que cuelga el instrumento.

Es posible que Picasso tuviese preparado el violín antes de realizar la composición, como sucedió con Guitarra y Botella (en la que utilizó la guitarra de cartón que ya tenía construida). La fotografía de un curioso montaje, Guitarrista, que nos muestra un lienzo de grandes dimensiones con una mesa delante, del que salen unos brazos realizados en papel de periódico sosteniendo una guitarra real y que podríamos considerar como un intento por asociar la construcción a un

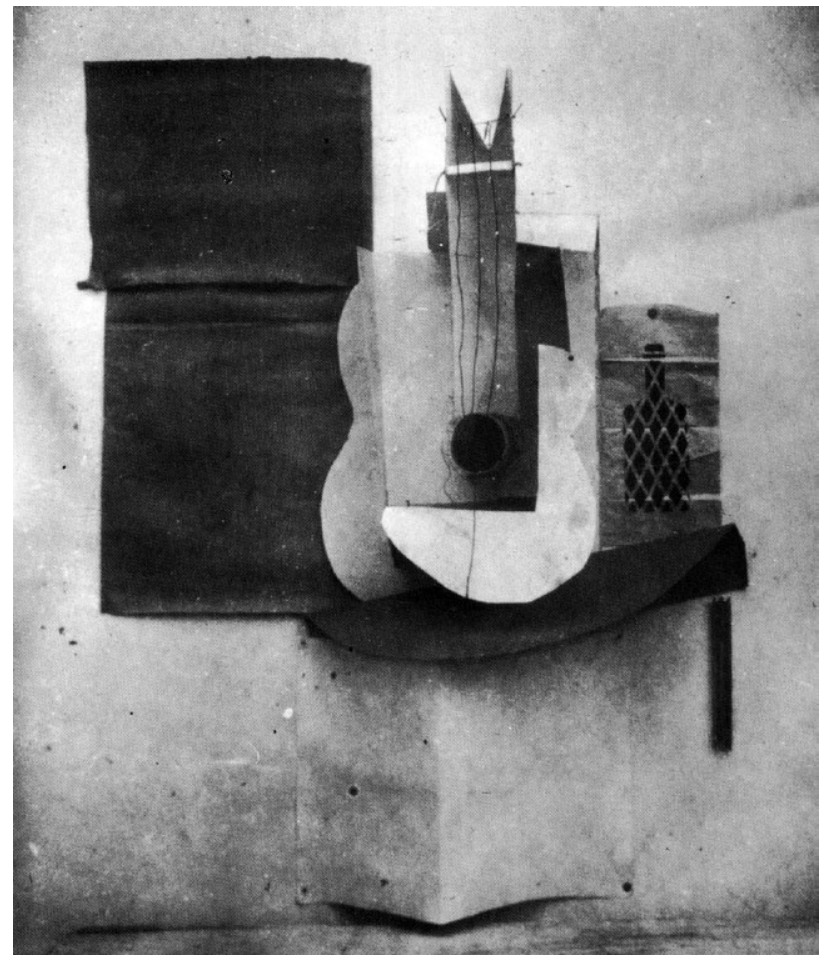

6. Guitarra y Botella. Picasso, otoño de 1913. Bramante, cartón y papel, $102 \times 80 \mathrm{~cm}$. Spies 48. Destruida
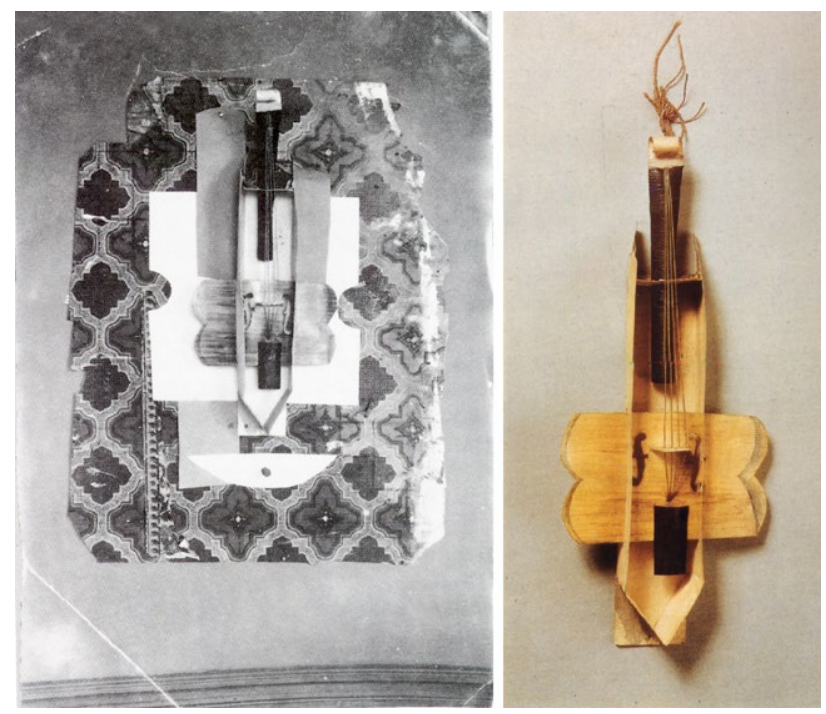

7. Violín. Picasso, 1913. Montaje sobre la pared de su estudio (izquierda) y estado actual (derecha) 


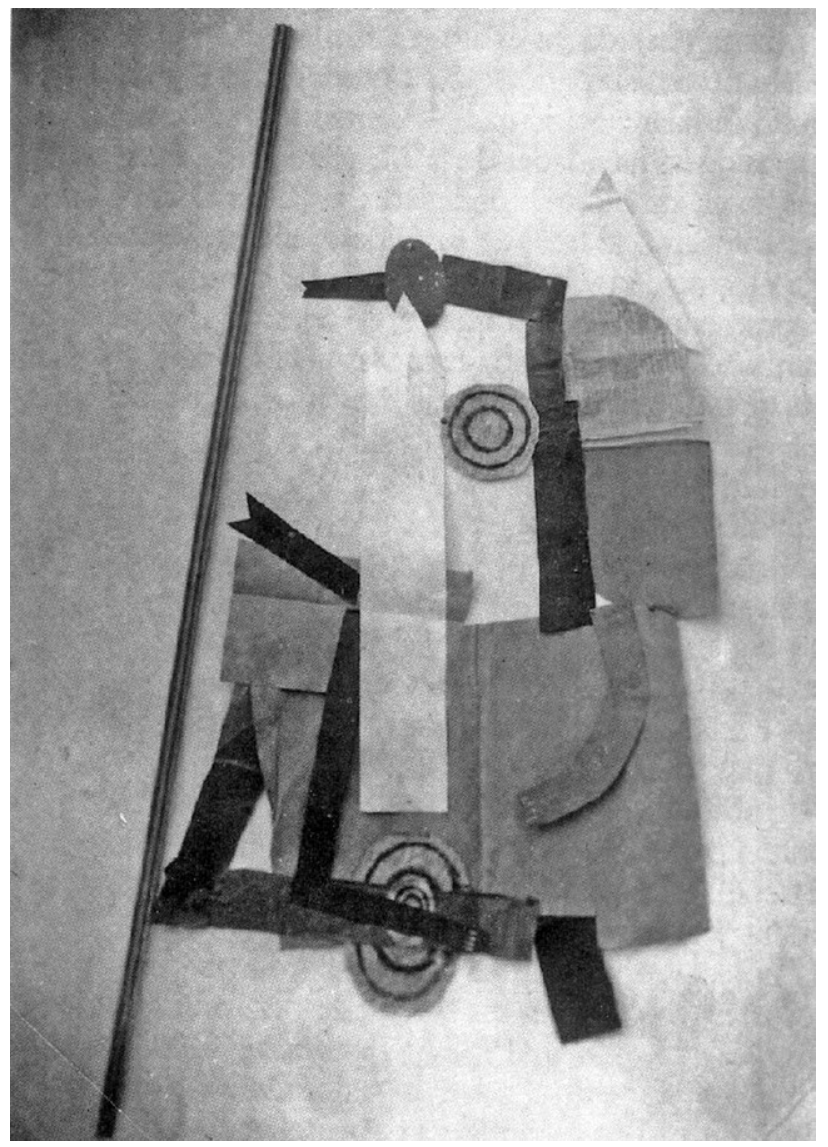

8. Guitarrista. Picasso, 1913 (destruida). Fotografía de Picasso. Archivos Picasso

espacio escénico, revela la presencia del violín, en la parte superior derecha del lienzo. La fotografía sin duda fue tomada en el estudio del boulevard Raspail, posiblemente en enero (de 1913); Picasso dejó el estudio a principios de octubre, por lo que al menos la realización del violín tuvo que ser anterior a esa fecha y por tanto anterior a la catalogación generalizada de la construcción completa, que la sitúa entre octubre-noviembre de 1913. Tanto en este caso como en el anterior, Picasso sólo conservaría los elementos tridimensionales de las composiciones, es decir, la guitarra y el violín, que guardaría para él, tal y como los había concebido inicialmente, recuperando de este modo su identidad original.

En todas las construcciones correspondientes a este periodo, la representación del espacio escénico o fondo es tratado del mismo modo que en sus papiers collés, utilizan- do para ello recortes de papel estampado o cartón, como un elemento bidimensional, dando lugar a lo que podríamos denominar un volumen plano, mientras que los objetos protagonistas de la escena, tanto la guitarra como el violín, son considerados volumétricamente, estableciéndose un contraste entre el tratamiento tridimensional de los objetos representados y el bidimensional del fondo en el que sitúa dichos objetos. Debemos tener en cuenta que las dos construcciones más representativas de este grupo (Guitarra y botella y Violín), surgen como evolución de anteriores trabajos, en el caso de Guitarra y botella, Picasso recurre a la célebre Guitarra de cartón, que posteriormente utilizó como plantilla para la versión realizada en chapa de hierro. La misma guitarra aparece ahora en una composición más abierta en la que se hace evidente el interés de Picasso por sintetizar el objeto como parte de la escena.

El carácter provisional y efímero de estos ejercicios dificultó considerablemente su conservación, por lo que algunos terminaron por desaparecer (Guitarrista [8]), o sufrieron severas mutilaciones, viéndose reducidas a los elementos protagonistas de las mismas (Guitarra y botella y Violín). Gertrude Stein, una de las pocas personas que en su momento supo valorar este tipo de trabajos a la altura del resto de su producción, conservó una pequeña delicia, Guitarrista con partitura [9], montada en una vitrina, tal vez gracias a ello ha llegado intacta hasta hoy.

A lo largo de este periodo Picasso continuará trabajando con materiales planos, fundamentalmente papel, y cartón, también utilizará la madera, pero en formatos igualmente planos (tablas, etc.). En ellos empieza a adquirir protagonismo la valoración tonal o cromática que ofrecen los diferentes materiales utilizados, lo que enriquece plásticamente la composición. Como sucede en Guitarrista (1913) [8], donde utiliza recortes de papel de diferentes tonalidades. Esta cualidad, heredada de sus papiers collés, confiere al material un doble sentido, convirtiéndolo en elemento constructivo, como generador de formas y volúmenes, y a su vez contribuyendo a determinar su apreciación cromática, en claro contraste con la uniformidad de sus primeras construcciones realizadas con un único material. El interés en el aprovechamiento del color le llevará a incorporar progresivamente nuevos materiales a sus composiciones, madera, hierro, e incluso objetos reales, desplazando con ello la presencia del papel que poco a poco perderá protagonismo. 
Sin duda, Picasso encontró en las esculturas realizadas en papel la respuesta a una alternativa artística transgresora, que rompiendo con muchos de los presupuestos plásticos del pasado, fuese capaz de reconciliar la escultura con la vanguardia del progreso. Según cita de Sabartés, escritor y gran amigo del artista desde su época de juventud, parafraseando a Picasso:

De este modo cuando hacíamos nuestras construcciones, producíamos «pura verdad», sin pretensiones, sin trucos, sin malicia, lo que nosotros hicimos entonces no se había hecho antes: lo hicimos desinteresadamente, y si esto vale de algo, es porque lo hicimos sin esperar sacar provecho de ello. Pretendíamos expresar la realidad con materiales que no sabíamos manipular, y que nos gustaban, debido precisamente a que sabíamos que su ayuda no nos era indispensable, que no eran los mejores ni los más adecuados (Sabartés, 1949: 241).

Estos trabajos y los realizados por su compañero Braque abrirán el camino a muchos e innovadores recursos escultóricos que se irán sucediendo a lo largo de los próximos años confiriendo una mayor amplitud al horizonte creativo de la expresión plástica. De este modo su influencia será reconocible en los trabajos de artistas como Vladimir Tatlin y sus contrarrelieves en una esquina, 1915, en los que adopta el sistema de escultura por construcción y recuerdan en su estrategia compositiva a Construcción de esquina, realizada por Braque en el Hotel Roma en la primavera de 1914 [1]. También Naum Gabo, junto con Tatlin figura destacable del movimiento constructivista ruso, deja constancia de su influencia en Cabeza construida n. ${ }^{0} 1,1915$, y Cabeza construida.$^{\circ}{ }^{2}$ 2, 1916, entre otras, realizadas en cartón y hierro respectivamente, y en las que adopta los mismos materiales y recursos constructivos empleados por Picasso en Guitarra de 1912 [5]. Del mismo modo artistas vinculados al movimiento dadaísta como Jean Arp, o Marcel Duchamp, se muestran en algunos aspectos de su trabajo deudores de estas técnicas y de la nueva orientación estética que suscitaron, como en las esculturas construidas en relieve, los collages o los papiers collés del primero, realizados durante la I Guerra

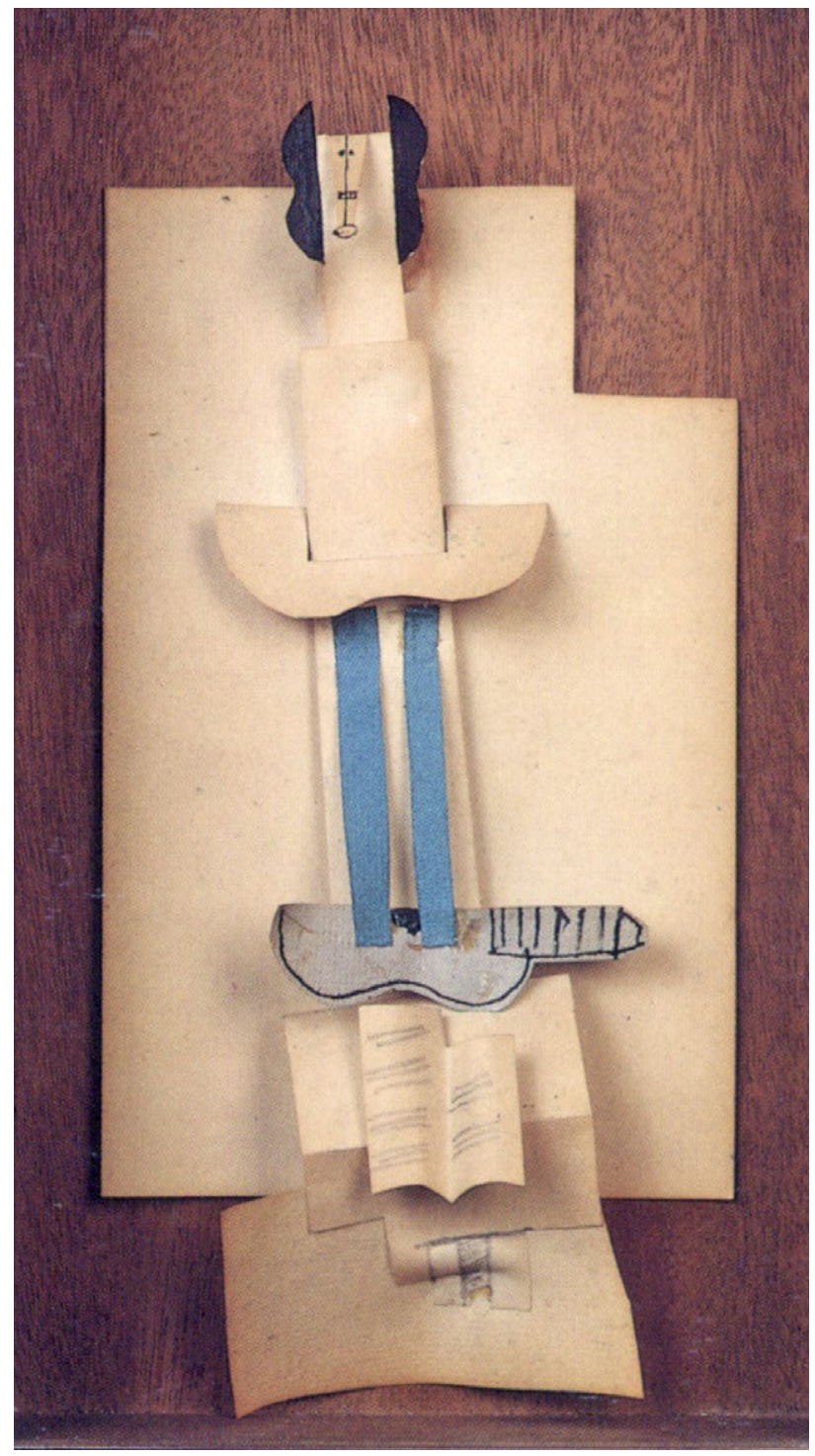

9. Guitarrista con partitura. Picasso, 1913. Papel y cartón (en la vitrina) 22 × 10, $5 \mathrm{~cm}$

Mundial, o la interesante fluctuación entre la realidad y la representación explorada por Duchamp en sus célebres ready mades, como herederos de collages de Picasso como Naturaleza Muerta con trenzado de silla, 1912, en los que también utiliza objetos extraídos de la realidad. 


\section{Bibliografía}

ARACIL, Alfredo y RODRÍGUEZ, Delfín (1982), El siglo XX. Entre la muerte del arte y el arte moderno, Istmo, Madrid.

BARR, Alfred H. Jr. (1989), La definición del arte moderno, Alianza Editorial, Madrid.

BOCOLA, Sandro (1999), El arte de la modernidad. Estructura y dinámica de su evolución de Goya a Beuys, Ediciones del Serbal, Barcelona. BÜRGER, Peter (1974), Teoría de la vanguardia, Editorial Península, Barcelona.

COWLING, Elizabeth y GOLDING, John (1994), Picasso: Sculptor/Painter, Tate Gallery Publications, Londres.

DAIX, Pierre (1995), Dictionnaire Picasso, Editions Robert Laffont, París.

DE MICHELI, Mario (1988), Las vanguardias artísticas del siglo XX, Alianza, Madrid.

FRANCASTEL, Pierre (1990), Arte y técnica en los siglos XIX y XX, Debate, Madrid.

GOLDING, John (1993), El cubismo, una historia y un análisis. 1907-1914, Alianza, Madrid.

GUTIÉRREZ BURÓN, Jesús (1990), Las claves del arte cubista, Planeta, Barcelona.

HENRY KAHNWEILER, Daniel (2013), El camino hacia el cubismo, Acantilado, Barcelona.

HOFMANN, Werner (1960), La escultura del siglo XX, Seix Barral, Barcelona.

KRAUSS, Rosalind E. (1999), Los papeles de Picasso, Gedisa, Barcelona.

LODDER, Cristina; MILNER, John; BASNER, Elena; DJAFÁROVA, Svetlana (1993), La vanguardia rusa 1905-1925, Fundación Central Hispano, Madrid.

NASH, J. M. (1975), El cubismo, el futurismo, y el constructivismo, Labor, Barcelona.

RICHARDSON, John (1997), Picasso. Una biografía. 1907-1917, Alianza, Madrid.

RUBIN, William (1991), Picasso y Braque: la invención del cubismo, Ediciones Polígrafa, Barcelona.

SABARTÉS, Jaime (1948), Picasso, an Intimate Portrait, Prentice-Hall, Londres.

SALMON, André (1956), Souvenirs sans fin. Deuxième époque (1908-1920), Gallimard, París.

SEDLMAYR, Hans (1990), La revolución del arte moderno, Mondadori, Madrid.

SPIES, Werner (1971), Esculturas de Picasso, obra completa, Gustavo Gili, Barcelona.

WARNCKE, Carsten-Peter (1995), Pablo Picasso 1881-1973, Taschen, Londres. 